\title{
Beyond Consensus: An Alternative use of Delphi Enquiry in Hospitality Research
}

\begin{abstract}
Purpose - To critically review the use of Delphi techniques in qualitative research for utilising 'expert' opinions and to explore through a detailed example, how Policy Delphi can be used by hospitality researchers as an alternative to the more widely used Normative Delphi.

Design/methodology/approach - This paper reflects on the research methodology of a project that explored organisational crisis signals detection using Policy Delphi with a criterion sample comprising 16 senior hotel executives involved in crisis management.

Findings - The main methodological concerns regarding Delphi are the definition of consensus, the expertise of the panel, its lack of scientific rigour, and -due to its lack of uniformity- reliability and validity of findings. Policy Delphi by default addresses the first since it does not seek consensus and can, through its design and execution, address the remaining concerns.

Research limitations/implications - Carefully designed Policy Delphi can offer a powerful research tool for exploratory research in hospitality, particularly for development of policies and strategies within an organisation. Unlike Normative Delphi, it is not intended as a decision making tool, but rather as a tool to generate options and suggest alternative courses of action for consideration.

Originality/value - The paper presents a valuable research tool that has evaded the attention of many hospitality researchers offering an illustrative example of its use in exploratory research to deliver credible, transferable and confirmable findings.
\end{abstract}

Keywords: Consensus building, crisis management, Policy Delphi, exploratory research, expert panel, critical incident technique. 


\section{Beyond Consensus: An Alternative use of Delphi Enquiry in Hospitality Research}

\section{Introduction}

As an area of research, crisis management started to receive attention in the 1980s. During this decade the frequency and magnitude of organisational crises and the subsequent impacts increased at an alarming rate (e.g., Bhopal, Tylenol, Chernobyl, Three Miles Island, Exxon Valdez) resulting in the emergence of a rich but relatively fragmented literature (Rasmussen \& Batstone, 1989).

Early crisis management research concentrated more on crisis and post-crisis communication (Schuetz, 1990; Seeger, 1986; Sellnow, 1993), the interrelationships between different stakeholders inside or outside organisations (Kabak \& Siomkos, 1990; Marcus \& Goodman, 1991) and the social control of organisations (Bromiley \& Marcus, 1989). Another stream analysed the nature of crises with Perrow (1984) attributing them to the technological complexity of organisations and other authors extending this idea to the combination of complex technological systems and the complex human systems that manage them (Bowonder \& Linstone, 1987; Pauchant \& Mitroff, 1992). In most cases, researchers used qualitative research designs based on analyses of cases, narratives, interviews and observations, alongside some quantitative analysis of surveys. Building on this early work, crisis management scholars proposed different models for the development of crises (Fink, 1986; Smith, 1990) and their management (Lagadec, 1987; Mitroff, et al., 1987). One of the, perhaps most significant, outcomes of these studies was Mitroff's (1988), framework for the management of a crisis, distinguishing five phases ("mechanisms" - in his terms): signal detection; preparation/prevention; containment (damage limitation); recovery; and learning.

The majority of crisis management literature published subsequently focused on the latter four phases, leaving the area of signal detection considerably under-explored. Notable exceptions included attempts to create early warning systems focusing mainly on natural disasters (e.g., Zschau \& Küppers, 2003), geophysics and financial markets (Sornette, 2004), financial crises (e.g., Berg \& Pattillo, 1999; Kaminsky et al, 1998) and organisational crises (Clair, 1993; Hensgen et al, 2003; Milenkovic, 2001). These studies produced mathematical and financial models of limited business utility as they were unable to prevent a series of crises which offered warning signals well ahead their escalation (Bradford, 2003; Choo, 2005; Thomas, 2006).

The wider research project from which this paper derives explored the concept of crisis signals detection in an organisational context. Rather than offering merely a conceptual framework of organisational crisis signal detection, the objectives of the study were to (1) identify the various component parts (building blocks) of a detection system and their location relative to the organisation, (2) propose forms of crisis detection and types of detectors to be used and (3) analyse the factors and conditions that would facilitate or inhibit the processes of capture, detection, and evaluation of organisational crisis signals. In order to achieve this, the researchers followed an inductive approach and used a variant of the Delphi technique, known as Policy Delphi with a group of sixteen senior hotel executives involved with crisis management. Drawing extensively on this 
project, the purpose of this paper is to critically review the use of Delphi techniques in qualitative research for utilizing 'expert' opinions and explore how Policy Delphi can be used by hospitality researchers as an alternative to the more widely used Normative Delphi. In so doing, provide insights into the use of Policy Delphi, a technique to date neglected by hospitality and tourism researchers.

\section{Research Context and Rationale}

The context of the research project was the hospitality industry with particular focus on international hotel groups. International hotel groups have been used as the context of numerous non-hospitality-specific studies mostly related with the management of retail and distribution, international strategies, branding and brand equity, consumer behaviour, intercultural management, organisational learning and new service development (e.g., Altinay, 2004; Olsen \& Sallis, 2006; Wirtz et al., 2000). The tourism industry in general is particularly vulnerable to crisis (Glaesser, 2003; Henderson, 2007) mainly due to the fact that it is a highly complex industry with huge interdependencies between its various actors that transcend national boundaries. Any event that causes instability in business life, local or international, even if not directly connected with tourism may have a large impact on the industry - be it a natural disaster, an act of terrorism, an epidemic, a political or financial crisis. International hotel groups as important actors in the tourism industry are largely affected by these events, often regardless of their geographical occurrence.

Crisis management research in hospitality and tourism has followed a course parallel to the 'mainstream' literature. At the time when 'mainstream' academics were analysing Tylenol, Bhopal and Three Miles Island, events such as the 1980 Mt. St. Helens eruption, the 1985 East Kootenay forest fires, the 1987 Fiji Coup, the 1989 San Francisco Earthquake and the 1989 Tienanmen Square massacre had such an impact on tourism that a stream of crisis/disaster research in hospitality and tourism was initiated. Early studies were invariably exploratory, usually describing such crisis events in detail and offering authors' analyses and participants' insights about the crises under investigation (Brewton, 1987; Burby \& Wagner, 1996; Drabek, 1994). Practices applied by authorities or tourism communities, were evaluated and suggestions made regarding the need for preparedness and crisis management planning. These were focused -with few exceptions- on media management, crisis communication and destination image recovery (e.g., Cammisa, 1993; Gonzales-Herrero \& Pratt, 1998; Milo \& Yoder; 1991; Young \& Montgomery, 1998). Impact studies from the same period explored the economic impact on tourism of natural disasters (Kreck, 1981), terrorism (Pizam \& Smith, 2000), the Asian financial crisis (Prideaux, 1999) and the war in Yugoslavia (Mihalic, 1999).

The same research foci in this area were followed by most hospitality and tourism researchers throughout the last decade, analysing mainly the causes of crises that affected tourism and industry responses (Henderson 2003; McKercher \& Chon, 2004; Taylor \& Enz, 2002), their impact on the industry (Blake \& Sinclair, 2003; Cavlek, 2002; Raab \& Schwer, 2003) and recovery strategies (Armstrong \& Ritchie, 2008; Beirman, 2003, Lo et al., 2006). Some initial attempts to develop a more strategic framework for managing crises in hospitality and tourism were made by Cassedy (1991) and then by Santana (1999), Faulkner (2001), Ritchie (2004), Paraskevas and Arendell (2007) and Hystad and 
Keller (2008). Yet, although these scholars acknowledged the different levels of planning (such as operational, organisational and strategic) and the different stages of crisis management (in accordance with Mitroff's 1988 approach) their models remained broad and did not clearly propose specific actions for each stage. Therefore, whilst signal detection may be mentioned or implied in these models, it remains completely unexplored.

\section{Research Methodology}

A large part of the aforementioned crisis management literature has relied upon the elicitation and the subsequent analysis of expert-participant opinion from individuals who were part of the crisis under study and had their own unique experiences and deep understandings of the issues of concern. In these cases, researchers construct knowledge through the collection of multiple sets of such interpretations, the combination of individual experts' experiences and understandings enabling common themes to be generated and insight gained (Becker, 1992). Central to this research approach is the inductive representation of a set of participants' experiences from which the researcher can build up a set of factual propositions, explanations and theories (Gill \& Johnson, 2010; Saunders et al., 2012). Invariably, emphasis is placed in the "process of interpretation" by which these outcomes are developed (Bogdan \& Taylor, 1975:14) as well as in the associated "audit trail" (Gill \& Johnson, 2010:172) to ensure possible concerns of subjectivity and bias are addressed. In interpreting such data, researchers therefore need to be aware of and make clear their own impact and the impact of the research process on the data interpretation. This raises challenges for qualitative researchers utilizing expert opinion. Alongside the need to build up factual propositions, explanations and theories, they must demonstrate the credibility, transferability and confirmability of their findings (Lincoln \& Guba, 1985), providing sufficient information to enable the impact of method on subsequent findings to be assessed.

Such challenges can, for some projects, be addressed through the use of research designs incorporating Normative or Policy Delphi techniques through which expert participants are involved in the data co-creation and interpretation. Of these, Normative Delphi is the most widely used and employed normally for building consensus on a specific real world issues (Hsu \& Sandford, 2007). Defined as a means for structuring group communication processes to address complex problems (Linstone \& Turoff, 2002), Normative Delphi provides a way of integrating anonymous experts' knowledge and by making use of their diverse and subjective judgements, opinions and experiences to achieve consensus. In contrast, Policy Delphi uses the experts' judgements, opinions and experiences to identify spread of opinion. However, despite its widespread real world applicability in areas such as strategy determination, resource utilisation and programme planning, the use of Policy Delphi within business management and, in particular hospitality and tourism research, has been minimal.

Given the scant research and limited literature on crisis signal detection in an organisational context, and the desire to involve expert participants in co-creation of knowledge and demonstrate transferability and confirmability a Delphi technique, was deemed as the most appropriate approach for this project. 


\section{Normative Delphi and Policy Delphi}

Normative Delphi, often referred to as 'Delphi' is a method for eliciting, aggregating and obtaining a consensus of expert opinion developed in the late 1950's and early 1960's by Norman Dalkey of RAND Corporation and Olaf Helmer of the Institute for the Future (Linstone \& Turoff, 2002). Normative Delphi was designed as a group decision mechanism utilizing a panel of qualified experts who have deep understanding of the issues of concern. These experts are defined as either top management decision makers, professional staff members together with their support team or other respondents whose judgments are being sought (Delbecq, et al., 1986). There is no recommended number of expert participants for the panel which can vary according to the scope of the problem and the available resources. Reports of studies record panels ranging in size from 10 to 1685 participants (e.g., Donohoe \& Needham, 2008; Reid 1988). Rather an essential characteristic of Normative Delphi is that expert-participants are anonymous throughout the study thereby eliminating possible influences by more prominent members of the group and providing each participant a non-threatening format (Moore, 1987).

A Normative Delphi consists typically of three to five rounds. In the first round, a questionnaire with open questions is sent to each participating expert. Their responses are analysed to generate a series of statements, which are incorporated into another questionnaire and, subsequently, sent to the individual experts asking them to rank their agreement with each. These rankings from the second round are summarised and included in a repeat version of the questionnaire which is sent back to the same experts who can now see how other panellist experts (who remain anonymous throughout the process) ranked statements and may decide to revise their own ranking. The process is repeated several times to develop a degree of consensus through iterative and controlled feedback (Delbecq et al., 1986). Although theoretically the Normative Delphi process can continue through as many subsequent rounds as needed to achieve consensus, three rounds are usually sufficient (Custer, Scarcella, \& Stewart, 1999).

In management, Normative Delphi has been used principally in applied research. For example, it was used as a forecasting tool by Milkovich et al. (1972) to generate manpower forecasts for a large US retail organisation and by Somers et al. (1984) to forecast training needs in an organisation. Ogden et al. (2005) used it to better understand which procurement and supply management strategies were most likely to lead to significant improvements over the next 5 to 10 years. It was also used as to identify 'best practice' in Wood and Ellis's (2003) exploration of the risk management practices of leading UK cost consultants. Normative Delphi has also been employed as a knowledge creation method to define and rank key barriers to the effective management of international manufacturing operations (Klassen \& Whybark, 1994), and to propose and articulate a theory of quality management describing and explaining the effects of adopting the Deming management method (Anderson et al. 1994). In marketing, it is used mainly in consumer behaviour studies, for example to identify criteria that determine the acceptability of new product (Padel \& Midmore, 2005) and to identify desirable product attributes (Huang \& Lin, 2005).

Within hospitality and tourism, Normative Delphi has, to date, been used predominantly to forecast tourism demand (e.g., Cunliffe, 2002; Edgell et al., 1980; Kaynak \& Macaulay, 1984; Yong et al., 1988) and, to a lesser extent, generate ideas, 
theories and practice related to hospitality and tourism management issues. For example, Mills and Hudson (1993) examined the characteristics of the new millennium foodservice manager, whilst Birdir and Pearson (2000) looked at basic competencies of research chefs; Murphy and Olsen (2009) used a two-round Delphi to validate restaurant work practice dimensions for a high performance management system; Garrod and Fyall (2000) explored constraints and imperatives relating to the long-term management of built heritage attractions; Miller (2001) used a two-round Delphi to develop indicators measuring movements in the tourism product's sustainability at a company/resort level; and Spenceley (2005) identified environmental factors that were essential to, or incompatible with, sustainable nature-based tourism in South Africa.

Normative Delphi has received considerable methodological criticism (Gupta \& Clarke, 1996). Sackman (1975:74) dismissed Normative Delphi for lack of scientific rigour and psychometric validity concluding that "the massive liabilities of Delphi, in principle and in practice, outweigh its highly doubtful assets". However, Normative Delphi supporters argued that this technique should not be used as a substitute for other scientific testing but as an alternative for complex subjects that other methods cannot resolve (Hsu \& Sandford, 2007). According to Coates (1975, cited in Linstone, 2002:559) the technique "is of value not in the search for public knowledge but in the search for public wisdom; not in the search for individual data but in the search for deliberative judgment".

One central question in the use of the Normative Delphi technique is the percentage agreement a researcher should accept as synonymous with consensus. Some researchers set out very explicit percentage cut-off points for consensus at the beginning of their study (e.g., Loughlin \& Moore, 1979 suggest that consensus should be equated to $51 \%$, whereas Green et al., 1999 use an 80\% consensus level). Others use an arbitrary cut off simply to limit the number of items considered. Rowe and Wright (1999) propose an alternative measure, the 'post-group consensus', which refers to the extent to which the panellist experts individually agree with the final group aggregate; their own final round rating and the ratings of other participants. Another area of concern is whether the reduction in variance of opinions over rounds reflects true consensus (that is a reasoned acceptance of a position by the panellist experts) or if this is 'false' consensus as a result of a drop out by discouraged dissenters whose disagreements were ignored (Hill \& Fowles, 1975; Linstone \& Turoff, 2002; Sackman, 1975).

The concerns over Normative Delphi's consensus highlighted the question of whether, in this research project, consensus was needed or if just 'broad agreement' among participants about the signal detection framework would be sufficient. It was felt that it was more important for the purpose of this study to adopt a technique that highlighted possible opposing views on the conditions that might potentially influence the effectiveness of crisis signal detection in an organisation rather than aiming for consensus based on a statistical aggregation of panellists' views (Dalkey \& Helmer, 1963). Consequently, rather than using Normative (aiming at consensus) Delphi approach as it originally was introduced, the researchers decided to use 'Policy Delphi'.

Policy Delphi was introduced by Turoff (1970) as a means of establishing "all the differing positions advocated and the principal pro and con arguments for those positions" (p. 153) rather than establishing the consensus of unbiased experts, and as a means of analysis instead of a tool for decision-making or prognostication (Turoff, 1970). 
Strauss and Zeigler (1975) did not overrule the possibility of consensus stating that the purpose of the Policy Delphi is to identify a variety of alternatives to a policy issue and to provide a constructive forum in which consensus might occur. However, Turoff (1970) suggests that this version of Delphi is more appropriate for researchers who are not interested in having the panel of experts generate the solution of the problem in hand but in having an informed group present all the options available with supporting evidence for their consideration.

Policy Delphi is a multistage process, the number of stages ranging between two and five (Critcher \& Gladstone, 1998). Turoff, (1970) suggested that the process normally requires at least "five rounds as opposed to the two or three that are usually sufficient for the technological type [normative] Delphi" (p. 161), however he recognised that multiple iterations can tire participants and lead to attrition (Table 1). In practice, Policy Delphi can usually be carried out effectively in three rounds by allowing the participants to add their own options and positions on the topic and their underlying assumptions or supporting arguments from the first round (Turoff, 2002).

\section{[Insert Table 1 about here]}

In the first round of Policy Delphi the researcher spends a significant amount of time identifying and recording issues and options derived from these issues according to the participants. McKenna (1994) maintained that, in this stage, face-to-face interviews greatly increase participation and investment in the project, especially with participants who are in leadership positions. This round is followed by data analysis, distribution of findings to all participants and design of a new research instrument (normally a questionnaire) based on the group response to the previous questions for a second measurement of opinions. Participants are allowed to add their own options and are asked for their positions on every option along with their reasons or supporting arguments. This process allows participants to reconsider their opinions in light of the views of other stakeholders and can be repeated until either consensus is reached or saturation of opinion occurs (Critcher \& Gladstone, 1998).

Policy Delphi has been used in public administration and business management research to examine, among other issues, consumer problems in a marketing system (Wikstrom, 1978), city planning and development in the Middle East (Smit \& Mason, 1990), public health issues (Rainhorn et al., 1994; O’Loughlin \& Kelly, 2004), public administration policies (Buck et al., 1993; Critcher \& Gladstone, 1998), taxation issues (Evans \& Walpole, 1999) and organisational strategic planning (Akkermans et al., 1999; Mara, 2000). However despite its use for identifying the spread of expert opinion, the authors have been unable to find examples of its use in hospitality research other than one presented here.

\section{Research Design}

\section{Sample Selection}

Dunn (1994) suggested that the participants in a Policy Delphi should be selected to represent a wide range of opinions. Studies employing Delphi techniques normally recruit participants who have advanced knowledge of the subject under investigation, hence the 
term 'panel of experts' (Linstone \& Turoff, 2002). One of the major areas of methodological debate with regards to Normative Delphi is the selection and participation of 'experts' (Hill \& Fowles, 1975; Sackman, 1975). Sackman (1975: 703) questioned the definition of an expert in a field arguing that "it is almost impossible to find current psychometric or social science literature on 'experts"'. Rowe and Wright (2001: 368) were also concerned with the participants' "absolute and relative" level of expertise and the way that this affects the results of Normative Delphi.

Policy Delphi overcomes this methodological hurdle by employing 'informed advocates' who have both knowledge and experience of the subject under investigation (Eggers \& Jones, 1998). However, although an 'informed advocate' may be knowledgeable about one aspect of a complex issue, they may not necessarily be able to formulate an opinion about the totality of the issue. Consequently, there is a need for participants' heterogeneity to be preserved to assure the validity of the results (Linstone $\&$ Turoff, 2002). Linstone (1978: 294) argued that in the formulation of national policy "...it is important to include in the Delphi representatives of a large or wide spectrum of vested interests, ranging from bureaucrats to minority groups". Policy Delphi studies, therefore usually employ purposive or criterion sampling (Hasson et al., 2000). Both these sampling methods assume researchers will have sufficient knowledge of the relevant population to select individuals that meet the purpose of their study. Purposive sampling allows researchers to use their judgement to select the participants that will best enable them answer their research questions (Saunders, 2012), whereas criterion samples are selected on the basis they meet a predetermined criteria of importance (Patton, 2002).

In our crisis signal detection study, the sample selected met three predetermined criteria: corporate level hospitality professionals in charge or directly involved with decisions related to risk/crisis management; working in a multi-unit national or international hotel chains; and having experienced at least one crisis incident in their organisations. The first criterion was necessary according to Patton (2002: 238) to distinguish between potential participants able to "...understand cases that are likely to be information-rich because they may reveal major system weaknesses that become targets of opportunity for program or system improvement". The second criterion provided the specific context in the study; whilst the third, Patton's (2002) 'criterion of importance', ensured relevant first-hand experience. In order to benefit fully from participants' crisis management expertise, the study explored critical incidents in organisations, a focus on specific events enabling participants to provide a full, detailed description of an experience as it was lived (Thompson et al., 1989). This allowed the subjective nature of the 'lived experience' of a crisis and its signal detection to be understood from the perspective of those experiencing it. Meanings could be explored alongside the explanations participants attributed to their experiences and their associated learning. An appropriate research design would elicit rich, descriptive and contextual detail to illustrate how the participants lived this experience, providing experientially based understanding of crisis signals in the particular incident. The study could then develop inductively a conceptualization of crisis signal detection in the context of a hotel chain.

Participants were recruited from the Global Council on Safety, Security and Crisis Management of the International Hotel and Restaurant Association (IH\&RA). Twenty two Council members matched the criteria for selection. However, for reasons ranging from increased workload and travelling commitments to high sensitivity of information to 
be shared, only sixteen agreed to participate. The size of the participants' group conformed to the guidelines given by Linstone (1978: 296) who suggested that "a suitable minimum panel size is seven" and Turoff (2002: 82) who maintained that "a Policy Delphi can be given to anywhere from ten to fifty people".

Within the prescribed context the group of participants was reasonably heterogeneous, participants varying in work background and years of experience (6-36 years), representing national and international hotel chains based in the Americas, Europe, Middle East and Africa (EMEA) and Asia Pacific (five companies being AngloAmerican). Although the group was male-dominated (only two female participants) this reflected industry norms. The participants' membership of the Global Council meant the challenge of 'quasi anonymity' was present, regardless of efforts to disguise persons, organisations and incidents.

\section{Round One of Policy Delphi: Issue Identification and Policy Options Available}

One major criticism of Normative Delphi based studies is what Stewart (1987), Rowe and Wright (2001) and Linstone (2002), among others, called 'sloppy execution' or 'simplification urge' in questionnaire design. They argued that the questionnaire used in the first round often contains far too simplistic statements or designs, associated tasks and measures being of uncertain relevance to the research purpose (Hill \& Fowles, 1975; Rowe \& Wright, 2001). Linstone (2002) noted that some questionnaires are too long or allow contradictions in responses. Rowe and Wright (2001) also highlighted the danger of structured first rounds in which statements are imposed to panellist experts without giving them the opportunity to indicate the issues they believe to be more important for the subject. In addition, poorly designed questionnaires in the first round have been found to have an adverse effect on participants who, as a result, often opt not to continue in the subsequent rounds (Webler et al., 1991).

In Policy Delphi, the first round may employ any appropriate method for data collection and, following McKenna's (1994) advice, this study used face-to-face interviews with the participants. This round was designed to incorporate phases 1-3 of the design suggested by Turoff (2002) (Table 1) namely: formulation of issues, exposing the options and, determining initial positions on the issues. Within each interview Critical Incident Technique (CIT) (Flanagan, 1954; Chell, 1998) was used to maximise the chance of capturing data about the most important conditions and issues. CIT is usually employed in the investigation of significant occurrences (events, incidents, or issues) which are identified by the interviewee, whom describes the way they are managed, and the outcomes in terms of perceived effects. "The objective is to gain understanding of the incident from the perspective of the individual, taking into account cognitive, affective, and behavioural elements" (Chell, 1998: 56). This allows participants to express their personal views of the described incident (Stauss \& Weinlich, 1997), its inductive nature especially when the topic has not been widely researched (Grove \& Fisk 1997), enabling powerful insights to be offered (Zeithaml \& Bitner, 2003). Moreover, its 'cultural neutrality' (de Ruyter et al., 1995), allows participants to offer their own perceptions on an issue, rather than indicate perceptions in response to researcher-initiated questions.

The CIT interviews in this study focussed on two discrete areas. The first asked participants to 're-live' a crisis they experienced; whereas the second explored these participants' insights about what was learnt from the crisis with particular focus on the 
early detection of possible warning signals. Through these interviews participants were encouraged to offer as many personal insights as possible about the factors and conditions that influence crisis signal detection.

To form a fuller picture of the context, details and effects of the critical incident on the organisation, content analysis was undertaken of documentary and other evidence provided by the participants from other sources. These included company documentation such as internal reports, consultancy reports, meeting minutes, memos and e-mails, policy statements, standard operating procedure manuals, training manuals, as well as video and audio recordings of Crisis Team meetings and training materials. The analysis of this material corroborated and augmented the evidence from the participants' accounts. Finally, articles and press coverage of the critical incidents were utilized whenever possible. In certain cases, analysis of secondary evidence indicated the need of a followup interview with a participant to clarify aspects of the critical incident. These follow-up interviews were granted whenever they were needed.

At the end of the interview cycle, participants' responses were transcribed verbatim and the transcripts returned to participants to be reviewed for content and interpretation accuracy. This 'member checking', helped establish credibility through establishing both internal (authenticity check) and external validity (transferability) in the overall process (Lincoln \& Guba, 1985). Any amendments made in the transcripts were considered primary data, the data they replaced being discarded. Verified transcripts were coded and analysed using N-Vivo 7 and a summary report sent to participants. The report presented anonymously all responses and included the themes that emerged, articulated as condition statements that would enable the timelier and more effective detection of crisis signals by an organisation. Each participant could distinguish her or his own response as it was highlighted in a different colour thereby addressing the criticisms of scarce feedback (Sackman, 1975) and "poor techniques of summarising and presenting the group response" (Linstone \& Turoff, 2002:6).

\section{Round Two of Policy Delphi: Measuring the Spread of Opinions}

The second round of Policy Delphi aimed to reveal participants' opinions about the condition statements that emerged from Round One and to explore the underlying assumptions, views, or facts used to support their respective positions (phases 4 and 5, Table 1). Turoff (2002) argues that since Policy Delphi deals predominantly with statements and comments, the most appropriate way for evaluating participants' ideas and opinions is to measure each against the four relative dimensions of desirability, feasibility, importance, and validity or confidence using four point rating scales. Desirability and feasibility ratings provoke discussions or debates among participants which may generate new options, whilst importance and validity ratings are used to evaluate underlying assumptions or supporting arguments. Turoff (2002: 86) suggests that neutral answers should not be offered, arguing that "the lack of a neutral point promotes a debate which is in line with developing pros and cons as one primary objective". Participants may however use the option of 'no judgement' where they consider that they have insufficient expertise to evaluate the statement or are not able to express any opinion about it.

A questionnaire was designed and distributed to participants requesting they evaluate, comment upon and rate each of condition statements developed in Round One using Turoff's (2002) four dimensions. Participants were also encouraged to add new 
conditions where they felt appropriate and suggest ways that these could be created in their organisation. Their ratings for each condition statement were summarised to determine the levels of agreement (or disagreement) for this round. Linstone \& Turoff (2002) argue that group agreement can be based on differing, or even opposing, assumptions and notes that failure to pursue these assumptions may lead to false conclusions. Individual comments were therefore consolidated and analysed in order to identify the underlying themes and assumptions.

A report was produced at the end of Round Two listing the modified condition statements and highlighting those where broad agreement was reflected, as well as points and rationale of disagreement. This modified and expanded list of condition statements, along with their associated comments, allowed participants to also have 'a feel' of the underlying reasons for responses.

\section{Round Three of Policy Delphi: Final Evaluation and Conclusion}

In the final round of Policy Delphi participants were asked to 'operationalise' their thoughts and views about how an effective crisis signal detection system should be planned in their own organisation. In doing this, they were instructed to take into consideration the points and rationale for disagreements expressed by the participants in the previous round, assess the relevance to their own organisations and propose actions for addressing them (phase 6 of Turoff's design, table 1).

For this round, participants were encouraged to act as representatives of their organisations rather than as individual anonymous participants (although anonymity was still maintained). This addressed criticisms that individuality and anonymity are often reasons for the lack of participant commitment who, behind their veil of anonymity, often rush "snap judgments" in the form of short or thoughtless written arguments instead of careful ponder and analysis of the issue (Sackman, 1975; Webler et al., 1991.). As a consequence, and having achieved a broad understanding about the conditions needed to be in place for effective crisis signal detection, each participant proposed an action plan for the development and refinement of their own organisation's signal detection process and practice (taking into consideration the disagreements and concerns highlighted in the report of Round Two). Subsequently, participants' responses were analysed and the proposed actions consolidated to produce a general plan for the development of effective organisational crisis signal detection.

\section{Findings}

The first round of this Policy Delphi was used to identify the conditions that affect the effectiveness of organisational crisis signal detection and determine the participants' views about them. Here the purpose was to elicit as many as possible differing views in order to create a 'rich picture' of crisis signal detection and ways that it can be improved. The spread of participants' opinions was, as expected, wide and even when they were talking about ostensibly the same topic they would often view it differently. For example, when participants referred to 'culture' in aggregate, they meant between one and four different types of culture, namely, management culture, occupational culture, crisis culture and information culture. The round yielded a number of conditions which were refined by the researchers and articulated in ten condition statements to be explored and 
further refined or enriched in the subsequent rounds. Another outcome of this round was a first identification of the detectors that can be part of the signal detection system as well as of the other building blocks of the detection system. In this part of the findings, the first elements of consensus appeared with regards to the different networks to be used. Alongside there were differences in opinions regarding potential detectors, reflecting differences in organisational culture, company size and budgets and participant's expertise.

The conditions identified in Round One were enriched and re-articulated, this time in eleven condition statements at the end of Round Two and were reconfirmed by the participants in Round Three as follows: Primarily the organisation needs to develop the right crisis culture which means that the organisation has to realise that it is vulnerable to a number of internal and external threats. Once this realisation is made, the organisation will understand that it needs to develop and actively support (with funding, tools and training) a quite complex network of detectors both internally and externally. This network will continuously scan the organisation's physical, information and cognitive domains. The signal detection process and practices as well the diversity of the detectors in the network need to continually evolve as crises themselves evolve and become more complex. One condition that will facilitate the more effective engagement of detectors in these networks is a decentralised, empowering management culture that favours continuous learning from own and other organisations' experiences. Such culture will enable the creation of genuine crisis awareness and vigilance as well as better use of the organisation's accumulated crisis knowledge for timely and effective response to the crisis signals. Decisions about action can be thus be collectively made (in network hubs) at local regional or senior management level. Technology plays an important role in the connectivity of the network through multiple horizontal and vertical communication platforms as well as in the decision making about signals though decision support systems and crisis knowledge databases that provide a repertoire of responses to different types of crises. In the case of unknown threats, the latter, can be used as a reference point that will facilitate the recognition of patterns of signals which will help the decision makers to make better sense of the emergent crisis and take appropriate action.

Although consensus was not sought in Policy Delphi and justification for differing opinions was shared among all participants, in these rounds the researchers encouraged a prioritisation of conditions and actions. In this prioritisation, a broad consensus was observed to emerge about how the detection system should be constructed and under which conditions it becomes more effective. Differences in opinions still existed; for example, some participants found that signal fusion hubs or that decision support systems were too expensive for their companies to afford. However, these elements were not considered primary for detection system design. Although some companies had them or were planning to incorporate them, they agreed that the system could work well even without them. It is noteworthy, however, that 'quasi anonymity' worked very much in favour rather than against the purpose of the study. The possibility that responses might be attributed to persons encouraged -even forced- the participants to be open and truthful, and in many cases to maintain their views until the final round, providing insightful information. It can be therefore argued that, in Policy Delphi, 'quasi anonymity' may reduce the threat of 'groupthink' or false consensus. The outcome of this round was a 
commonly agreed Crisis Signal Detection Framework offering a 'bird's eye' view of an organisation's crisis detection system.

Further analysis of the participants' responses in these rounds resulted in the classification of human detectors in an Organisational Crisis Detector Typology. This was considerably different from those presented in the extant crisis management literature, since, apart from the relative location of the detector, this typology considers two more dimensions: crisis specialism and the strength of the detector's ties with the organisation. The differing opinions of the participants allowed the classification of detectors into core, ad hoc and expert networks and will help crisis managers in prioritising the detectors to be included in the system according to the organisation's needs.

Finally, Round Three showed that the development of a signal detection system can be 'operationalised' through a gradual process which 'matures' in five stages as proposed by the Signal Detection Maturity Model which resulted from this round. Again, the difference of opinions about what is more important, feasible and desirable as the organisation's signal detection strategy matures allowed the creation of this model.

\section{Discussion: Validity and Reliability of Policy Delphi}

In their discussion of the validity of constructionist research designs Easterby-Smith et al. (2008: 97) emphasise that the results should be believable and reached through methods that are transparent. Although precise replicability of Policy Delphi cannot be guaranteed, every effort was made that the various stages of the study ensured the reliability and validity of the findings. The criteria used here were based on Lincoln and Guba (1985) who propose: credibility (in place of internal validity); transferability (in place of external validity); dependability (in place of reliability); and confirmability (in place of objectivity).

The credibility of Policy Delphi was ensured first through the selection and use of an expert participant panel as in this study's sample. The criteria for selection were clear and relevant to the study and the possibility of bias was not considered significant as the panel was reasonably heterogeneous. Other steps to ensure the credibility of the study included the use of multiple sources of evidence in order to understand and interpret the context, causes and consequences of the critical incidents reported by the experts and the member checking employed during the first round of Policy Delphi. The credibility of the overall Policy Delphi findings was also increased by the confirmation of the 'conditions' through a process of decision, strengthened by reasoned argument in which assumptions were challenged and tested by participants in successive rounds.

Transferability of findings was ensured by what Lincoln and Guba (1985: 362) term a 'thick description'. Through "thorough description of the context or setting within which the inquiry took place" and of "the transactions or processes observed in that context". Participants were able to assess the relevance of conditions to their own organisations and, subsequently, the consolidation of their responses into a general plan. Since the study was designed to solicit experiences and opinions of experts in the field, the likelihood that the resulting findings could be transferred to other contexts and settings was increased.

Dependability was ensured primarily by the iterative feedback with the participants. This is at the core of the Policy Delphi technique and also helps minimise possible 
researcher bias through the use of participants as independent "judges" in establishing reliable condition statements in the end of the first round. Finally, confirmability was ensured first by the findings and proposed model being grounded in the data collected; second, by all inferences, categorisations and analyses being confirmed by the participants and, third, by transparency of the method used and how sense was made of the data.

\section{Conclusion}

The focus of this paper is purposefully on Policy Delphi since this technique has, until now, received no interest from hospitality researchers. The paper provides a number of insights into Policy Delphi and offers the first illustration of how it can be used as an alternative technique for researching complex subjects.

Unlike the more widely known Normative Delphi that is often used as forecasting or a decision making tool based on the consensus of expert-participants, Policy Delphi is a research technique which seeks more to explore possible alternatives, identify and seek the range of opinions on the issues that were germane to the research topic, and to potentially emerge with a consensus on key issues.

Situations that appear particularly suited to Policy Delphi include those where new strategies or policies are sought and there is a need to explore or expose underlying assumptions, opinions or gather information to support new strategic or policy directions. For example, in the development of a marketing communications strategy for a tourism destination where multiple stakeholders (hoteliers, tour operators, airlines, local tourism authorities, etc.) or in the development of a delegation of authority policy within an organisation, it is recognised that the idea of unbiased technical expertise does not apply as both these issues are defined by conflicting special interests. Moreover, where it is unlikely that consensus can be created, Policy Delphi can be used to identify the breadth of differing opinions. Through the iterative processes of prioritising elements of the strategy/policy in terms of confidence, importance, feasibility and desirability, Policy Delphi can either facilitate a trend of consensus or allow informed decisions to be made for the benefit of the majority of the involved parties. By default, this also removes the need to determine explicit percentage cut-off points for consensus. Policy Delphi can also be used to construct a feedback system that channels views and opinions of the various stakeholders with the goal of developing a more realistic and implementable policy. It is also likely to be of use in situations where management needs to find out the extent of diversity in opinions, or where the researcher is unaware of the full spectrum of issues and literature offers insufficient information.

From a methodological perspective Policy Delphi offers researchers more flexibility than Normative Delphi. Rather than having to recruit proven 'experts' on the research topic, a wide range of 'informed' participants are required to ensure the maximum possible heterogeneity of the sample of informants. It also does not confine the first round of data collection to the prescribed in Normative Delphi surveys or questionnaires.

The anonymous recording of opinions and their use throughout the process without any urge to reach consensus appeared to have a positive effect on participant retention at all the stages of the study. The feedback structure of the technique allowed a focus upon issues that are often disregarded by the influence of powerful or vocal special interests 
and can set the stage for constructive debate. These characteristics can make the Policy Delphi particularly attractive not only to researchers but to government officials and policy makers.

Although it is still the researcher's responsibility to provide sufficient information to enable the impact of research method to be assessed, unlike interviews, observation and focus groups, participants both remain anonymous and are actively involved in data generation and interpretation. This offers a significant advantage when undertaking inductive research by reducing the influence of dominant individuals on outcome. At the same time participants' active involvement in the iterative interpretation processes of either reaching consensus or establishing the spread of opinion, further support the credibility, transferability, dependability and confirmability of findings. Policy Delphi allows researchers to observe unforced shifts of opinion (again because consensus is not the objective) about different aspects of the topic in the course of a study by considering how participants' desirability, feasibility, importance, and confidence ratings or their general stance towards an issue alter.

Finally, future exploratory studies on policy and strategy development in hospitality and tourism destination contexts would do well to consider the use of Policy Delphi as a tool to generate options and suggest alternative courses of action. Sample selection allows incorporation of the multiplicity of interests involved, recognising the value of different kinds of front-line expertise. Subsequent exploration of the distribution of opinions and reasons for these and the development and testing of condition statements enables both researchers and policy makers to expand their knowledge and understanding of the issue under investigation, isolate underlying reasons for non-constructive opinions and derive participant confirmed transferable findings.

\section{References}

Akkermans, H., Bogerd, P. and Vos, B. (1999). Virtuous and Vicious Cycles on the Road Towards International Supply Chain Management. International Journal of Operations and Production Management, Vol. 19, No. 5/6, pp. 565-581.

Altinay, L. (2004). Implementing International Franchising: The Role of Intrapreneurship. International Journal of Service Industry Management, Vol. 15, No.5, pp. 426-443.

Anderson, J. C., Rungtusanatham, M. and Schroeder, R.G. (1994). A Theory of Quality Management Underlying the Deming Management Method, Academy of Management Review, Vol. 19, No. 3, pp. 472-509.

Armstrong, K.E. and Ritchie, B.W. (2008) The Heart Recovery Marketing Campaign: Destination Recovery After a Major Bushfire in Australia's National Capital, Journal of Travel and Tourism Marketing, Vol. 23, Nos. 2,3,4, pp. 175-189.

Becker, C.S. (1992). Living and Relating: An Introduction to Phenomenology. Newbury Park, CA: Sage Publications.

Beirman, D. (2003). Restoring Tourism Destinations in Crisis. A Strategic Marketing Approach, Wallingford: CABI.

Berg, A. and Pattillo, C. (1999). Predicting Currency Crises: The Indicators Approach and an Alternative, Journal of International Money and Finance, Vol. 18, No. 4, pp. 561-586.

Birdir, K. and Pearson, T.D. (2000). Research Chefs' Competencies: A Delphi Approach. International Journal of Contemporary Hospitality Management. Vol. 12, No. 3, pp. 205209. 
Blake, A. and Sinclair, T. M. (2003). Tourism Crisis Management: US response to September 11, Annals of Tourism Research, Vol. 30, No. 4, pp. 813-832.

Bogdan, R. and Taylor, S. J. (1975). Introduction to Qualitative Research Methods: A Phenomenological Approach to the Social Sciences. New York: Wiley.

Bowonder, B. and Linstone, H.A. (1987). Notes on the Bhopal accident: Risk Analysis and Multiple Perspectives. Technological Forecasting and Social Changes, Vol. 32, No. 2, pp. 183-202.

Bradford, L. (2003). Fat Foods: Back in Court: Novel Legal Theories Revive the Case Against McDonald's, Time On Line Edition, 03 August. Available at: http://www.time.com/time/insidebiz/article/0,9171,1101030811-472858,00.html, accessed 10 October, 2008.

Brewton, C. (1987). Managing a crisis: a model for the lodging industry, Cornell Hotel and Restaurant Administration Quarterly, Vol. 28, No. 3, pp. 10-14.

Bromiley, P. and Marcus, A. (1989). The Deterrent to Dubious Corporate Behavior: Profitability, Probability and Safety Recalls. Strategic Management Journal, Vol. 10, No. 3, pp. 233-250.

Buck, A.J., Gross, M., Hakim, S. and Weinblatt, J. (1993). Using the Delphi Process to Analyze Social Policy Implementation: A Post Hoc Case from Vocational Rehabilitation. Policy Sciences, Vol. 26, No. 4, pp. 271-288.

Burby, R.J. and Wagner, F. (1996) Protecting Tourists from Death and Injury in Coastal Storms, Disasters, Vol. 20, No. 1, pp. $49-60$.

Cammisa, J. V. (1993). The Miami experience: natural and man-made disasters, 1992-93, Expanding Responsibilities: A Blueprint for the Travel Industry, Travel and Tourism Research Association, 24th Annual Conference Proceedings, Whistler, BC, pp. 294-95.

Cassedy, K. (1991) Crisis Management Planning in the Travel and Tourism Industry: A study of three destinations and a crisis management planning manual, San Francisco, PATA.

Cavlek, N. (2002). Tour Operators and Destination Safety. Annals of Tourism Research, Vol. 29, No. 2, pp. 478-496.

Chell, E. (1998). Critical Incident Technique. In G. Symon and C. Cassell (eds.). Qualitative Methods and Analysis in Organizational Research: A Practical Guide, London: Sage, pp. 51-72.

Choo, C.W. (2005). Information Failures and Organizational Disasters. Sloan Management Review, Vol. 46, No. 3, pp. 8-10

Clair, J. A. (1993). Turning Poison into Medicine: A Grounded Theoretical Analysis of Processes, Pathologies, and Designs in the Detection of Potential Organizational Crises. Unpublished Doctoral Dissertation, University of Southern California.

Critcher, C. and Gladstone, B. (1998). Utilizing the Delphi Technique in Policy Discussion: A Case Study of a Privatized Utility in Britain. Public Administration, Vol. 76, No.3, pp. 431-449.

Cunliffe, S. (2002). Forecasting risks in the tourism industry using the Delphi technique. Tourism, Vol. 50, No. 1, pp. 31-41.

Custer, R. L., Scarcella, J. A., \& Stewart, B. R. (1999). The modified Delphi technique: A rotational modification. Journal of Vocational and Technical Education, Vol. 15, No. 2, pp. $1-10$.

Dalkey, N. and Helmer, O. (1963). An Experimental Application of the Delphi Method to the Use of Experts. Management Science, Vol. 9, No. 3, pp. 458-467.

De Ruyter, K., Perkins, D.S. and Wetzels, M. (1995). Consumer-Defined Service Expectations and Post Purchase Dissatisfaction in Moderately-Priced Restaurants: A Cross-National Study. Journal of Consumer Satisfaction, Dissatisfaction, and Complaining Behavior, Vol. 8, No. 1, pp. 177-187. 
Delbecq, A.L., Van de Ven, A.H. and Gustafson, D.H. (1986). Group Techniques for Program Planning: A Guide to Nominal Group and Delphi Processes, Middleton, WI: Green Briar Press.

Donohoe, H.M. and Needham, R.D. (2008). Moving Best Practice Forward: Delphi Characteristics, Advantages, Potential Problems, and Solutions. International Journal of Tourism Research, Vol. 11, No. 5, pp. 415-437.

Drabek, T. E. (1995). Disaster responses within the tourism industry, International Journal of Mass Emergencies and Disasters, Vol. 13, No. 1, pp. 7-23.

Dunn, W.N. (1994). Public Policy Analysis: An Introduction (2nd ed.). Englewood Cliffs, NJ: PrenticeHall.

Easterby-Smith, M., Thorpe, R. and Jackson, P.R., (2008), Management Research, $3^{\text {rd }}$ edition, London: Sage Publications.

Edgell, D.L., Seely, R.L. and Iglarsh, H.J. (1980), Forecasts of International Tourism to the USA, International Journal of Tourism Management, Vol. 1 No.2, pp.109-13.

Eggers, R.M. and Jones, C.M. (1998). Practical Considerations for Conducting Delphi Studies: The Oracle Enters a New Age. Educational Research Quarterly, Vol. 21, No. 3, pp. 53-66.

Evans, C. and Walpole, M. (1999). Compliance Cost Control: A Review of Tax Impact Statements in the OECD, (Research Study No. 27). Sydney: Australian Tax Research Foundation.

Faulkner, B. (2001). Towards a Framework for Tourism Disaster Management, Tourism Management, Vol. 22, No. 2, pp. 135-147.

Flanagan, J.C. (1954). The Critical Incident Technique, Psychological Bulletin, Vol. 51, No. 4, pp. 327-58.

Garrod, B. and Fyall, A. (2000). Managing Heritage Tourism, Annals of Tourism Research, Vol. 27, No. 3, pp. 682-708.

Gill, J. and Johnson, P., (2010). Research Methods for Managers, 4th edition. London: Sage Publishing.

Glaesser, D. (2003). Crisis Management in the Tourism Industry. Oxford: Butteworth-Heinemann.

Gonzales-Herrero, A. and Pratt, C.B. (1998). Marketing Crises in Tourism: Communication Strategies in the United States and Spain. Public Relations Review, Vol. 24, No.1, pp. 8397.

Green B., Jones M., Hughes D. and Williams A. (1999). Applying the Delphi Technique in a Study of GPs Information Requirements. Health and Social Care in the Community, Vol. 7, No. 3, pp. 198-205.

Grove, S.J. and Fisk, R.P. (1997). The Impact of Other Customers on Service Experiences: A Critical Incident Examination of 'Getting Along', Journal of Retailing, Vol. 73, No.1, pp. 63-85.

Gupta, U.G. and Clarke, R.E. (1996). Theory and Applications of the Delphi Technique: A Bibliography (1975-1994). Technological Forecasting and Social Change, Vol. 53, No.2, pp. 185-211.

Hasson, F., Keeney, S., and McKenna, H. (2000). Research Guidelines for the Delphi Survey Technique. Journal of Advanced Nursing, Vol. 32, No. 4, pp. 1008-1015.

Henderson, J.C. (2003). Terrorism and Tourism: Managing the Consequences of the Bali Bombings, Journal of Travel \& Tourism Marketing, Vol. 15, No. 1, pp. 41-58.

Henderson, J.C. (2007). Tourism Crises: Causes, Consequences and Management, Oxford: Butterworth-Heinmenann.

Hensgen, T., Desouza K.C. and Kraft, G.D. (2003). Games, Signal Detection, and Processing in the Context of Crisis Management, Journal of Contingencies and Crisis Management, Vol. 11, No. 2, pp. 67-77.

Hill, K.Q. and Fowles, J. (1975). The Methodological Worth Of The Delphi Forecasting Technique, Technological Forecasting and Social Change, Vol. 7, No. 2, pp. 179-192. 
Hsu, C-C and Sandford, B.A. (2007). The Delphi Technique: Making Sense of Consensus, Practical Assessment, Research and Evaluation, Vol. 12, No. 10, pp. 1-8. Available from http://pareonline.net/pdf/v12n10.pdf [Accessed 28 September 2010].

Huang, E.Y. and Lin, C.Y. (2005). Customer-oriented Financial Service Personalization. Industrial Management and Data Systems, Vol. 105, No. 1, pp. 26-44.

Hystad, P.W. and Keller, P.C. (2008). Towards a Destination Tourism Disaster Management Framework: Long-Term Lessons from a Forest Fire Disaster, Tourism Management, Vol. 29, No. 1, pp. 151-162.

Kabak, I.W. and Siomkos, G. (1990). How Can an Industrial Crisis be Managed Effectively? Industrial Engineering, Vol. 22, No. 6, pp. 18-21.

Kaminsky, G., Lizondo, S. and Reinhart, C. (1998). Leading Indicators of Currency Crisis, IMF Staff Papers, International Monetary Fund, Vol. 45, No. 1, March, pp. 1-48.

Kaynak, E. and Macaulay, J.A. (1984). The Delphi Technique in the Measurement of Tourism Market Potential, Tourism Management, Vol. 5, No.2, pp. 87-101.

Klassen R.D. and Whybark D.C. (1994). Barriers to the Management of International Operations. Journal of Operations Management, Vol. 11, No. 4, pp. 385-396.

Kreck, L.A. (1981). When Mt. St. Helens Blew Its Top, Journal of Travel Research, Vol. 19, No. 4, pp. 16-22.

Lagadec, P., (1987). Communications Strategies in Crisis. Industrial Crisis Quarterly, Vol. 1, No. 1, pp. 19-26.

Lincoln, Y. and Guba, E. (1985). Naturalistic Inquiry. Beverly Hills, CA: Sage Publications.

Linstone, H.A. (1978). The Delphi Technique. In R.B. Fowles (Ed.), Handbook of Futures Research, Westport, CT: Greenwood, pp. 271-300.

Linstone, H.A. and Turoff, M. (Eds.). (2002). The Delphi Method: Techniques and Applications. Reading, MA: Addison-Wesley.

Lo, A., Chung, C. and Law, R. (2006). The survival of hotels during disaster: A case study of Hong Kong in 2003, Asia Pacific Journal of Tourism Research, Vol. 11, No. 1, pp. 65-79.

Loughlin K.G. and Moore L.F. (1979). Using Delphi to Achieve Congruent Objectives and Activities in a Paediatrics Department. Journal of Medical Education, Vol. 54, No. 2, pp. 101-106.

Mara, C.M. (2000). A Strategic Planning Process for a Small Nonprofit Organization. Nonprofit Management and Leadership, Vol. 11, No. 2, pp. 211-223.

Marcus, A.A., and Goodman, R.S. (1991). Victims and Shareholders: The Dilemmas of Presenting Corporate Policy During a Crisis. Academy of Management Journal, Vol. 34, No. 5, pp. 281-305.

McKenna, H.P. (1994). The Delphi Technique: A Worthwhile Research Approach for Nursing? Journal of Advanced Nursing, Vol. 19, No. 6, pp. 1221-1225.

McKercher, B. and Chon, K. (2004) The over-reaction to SARS and the Collapse of Asian Tourism, Annals of Tourism Research, Vol. 31, No. 3, pp. 716-719.

Mihalic, T. (1999). Tourism Drop and Recovery After the War: The Case of Slovenia, Turizam, Vol. 47, No. 1, pp. 61-66.

Milenkovic, G. (2001). Early Warning of Organisational Crises: Research Project from the International Air Express Industry, Journal of Communication Management, Vol. 5, No. 4, pp. 360-373.

Milkovich, G.T., Annoni, A.J. and Mahoney, T.A. (1972). The Use of the Delphi Procedures in Manpower Forecasting. Management Science, Vol. 19, No. 4, Application Series, Part 1, pp. 381-388.

Miller, G. (2001). The Development of Indicators for Sustainable Tourism: Results of a Delphi Survey of Tourism Researchers. Tourism Management, Vol. 22, No. 3, pp. 351-362.

Mills, S.F. and Hudson, R. (1993). Foodservice Manager 2000, Journal of Hospitality and Tourism Research, Vol. 17, No.1, pp. 147-159. 
Milo, K.J. and Yoder, S.L. (1991) Recovery from Natural Disaster: Travel Writers and Tourist Destinations, Journal of Travel Research, Vol. 30, No. 1, pp. 36-39.

Mitroff, I.I. (1988). Crisis Management: Cutting through the Confusion. Sloan Management Review. Winter, pp. 15-20

Mitroff, I.I., Shrivastava, P. and Udwadia, F.E. (1987). Effective Crisis Management. Academy of Management Executive, Vol. 1, No. 3, pp. 283-292.

Moore, C.M. (1987). Group Techniques for Idea Building, Newbury Park, CA: Sage Publishing.

Murphy, K. and Olsen, M. (2009). Dimensions of a High Performance Management System: An Exploratory Study of the US Casual Restaurant Segment. International Journal of Contemporary Hospitality Management. Vol. 21, No. 7, pp. 836-853.

O'Loughlin, R. and Kelly, A. (2004). Equity in Resource Allocation in the Irish Health Service: A Policy Delphi Study, Health Policy, Vol. 67, No.3, pp. 271-279.

Ogden, J.A., Petersen, K.J., Carter, J.R. and Monczka, R.M.(2005). Supply Management Strategies for the Future: A Delphi Study. Journal of Supply Chain Management. Vol. 41, No. 3, pp. 29-48.

Olsen, N.V. and Sallis, J. (2006). Market Scanning for New Service Development. European Journal of Marketing, Vol. 40, No. 5/6, pp. 466-484.

Padel, S. and Midmore, P. (2005). The Development of the European Market for Organic Products: Insights from a Delphi Study. British Food Journal, Vol. 107, No. 8, pp. 626-646.

Paraskevas, A. and Arendell, B. (2007) A Strategic Framework for Terrorism Prevention and Mitigation in Tourism Destinations, Tourism Management, Vol. 28, No. 6, pp. 1560-1573.

Patton, M. (2002). Qualitative Research and Evaluation Methods. 3rd edition. Thousand Oaks, CA: Sage Publications.

Pauchant, T.C. and Mitroff, I.I. (1992). Transforming the Crisis Prone Organization: Preventing Individual, Organizational and Environmental Tragedies, San Francisco: Jossey-Bass.

Perrow, C. (1984). Normal Accidents: Living with High-Risk Technologies, New York: Basic Books.

Pizam, A. and Smith, G. (2000). Tourism and terrorism: A Quantitative Analysis Of Major Terrorist Acts And Their Impact On Tourism Destinations, Tourism Economics, Vol. 6, No. 2, pp. 123-138.

Prideaux, B. (1999). The Asian financial crisis: Causes and implications for Australia's tourism industry. The Australian Journal of Hospitality Management, Vol. 6, No. 2, pp. 35-44.

Raab, C. and Schwer, R.K. (2003). The Short- and Long-term Impact of the Asian Financial Crisis on Las Vegas Strip Baccarat Revenues, International Journal of Hospitality Management, Vol. 22, No. 1, pp. 37-45.

Rainhorn, J., Brudon-Jakobowicz, P. and Reich, M. (1994). Priorities for Pharmaceutical Policies in Developing Countries: Results of a Delphi Survey, Bulletin of World Health Organisation, Vol.72, No.5, pp. 257-264.

Rasmussen, J., and Batstone, R. (1989). Why Do Complex Organizational Systems Fail? Proceedings of a Cross-Disciplinary Workshop in Safety Control and Risk Management. Washington, D.C.: World Bank.

Reid, N. (1988). The Delphi technique: its contribution to the evaluation of professional practice. In Ellis R. (ed.) Professional Competence and Quality Assurance in the Caring Professions. London: Chapman \& Hall, pp. 230-254.

Ritchie, B.W. (2004). Chaos, Crises and Disasters: A Strategic Approach to Crisis Management in the Tourism Industry, Tourism Management, Vol. 25, No. 6, pp. 669-683.

Rowe, G. and Wright, G. (2001), Expert Opinions in Forecasting: Role of the Delphi Technique. In J.S. Armstrong (Ed.), Principles of Forecasting. Norwell, MA: Kluwer Academic Press, pp. 125-144.

Sackman, H. (1975). Delphi Critique, Lexington, MA: Lexington Books. 
Santana, G. (1999). Tourism: Towards a Model for Crisis Management. Tourizam, Vol. 47, No. 1, pp. 4-12.

Saunders, M.N.K. (2012). Choosing research participants In C. Cassell and G. Symons (eds.). The Practice of Qualitative Organizational Research: Core Methods and Current Challenges. London: Sage, pp. 37-55.

Saunders, M.N.K., Lewis, P. and Thornhill, A. (2012). Research Methods for Business Students. $\left(6^{\text {th }}\right.$ edn.) Harlow: Pearson Education.

Schuetz, J. (1990). Corporate Advocacy as Argumentation. In R. Trapp and J. Schuetz (eds.). Perspectives on Argumentation. Prospect Heights, IL: Waveland Press, pp. 272-284.

Seeger, M.W. (1986), The Challenger Tragedy and Search for Legitimacy, Central States Speech Journal, Vol. 37 No. 3, pp. 147-157.

Sellnow, T.L. (1993). Scientific Argument in Organizational Crisis Communication: The Case of Exxon. Argumentation and Advocacy, Vol. 30, No. 1, pp. 28-43.

Smit, J. and Mason, A. (1990). A Policy Delphi Study in the Socialist Middle East. Public Administration and Development, Vol. 10, No. 4, pp. 453-465.

Somers, K., Baker, G., and Isbell, C. (1984). How to Use the Delphi Technique to Forecast Training Needs. Performance and Instruction Journal. Vol. 23, No.1, pp. 26-28.

Sornette, D. (2004). Why Stock Markets Crash: Critical Events in Complex Financial Systems. Princeton, NJ: Princeton University Press.

Spenceley, A. (2005). Nature-based Tourism and Environmental Sustainability in South Africa, Journal of Sustainable Tourism, Vol. 13, No. 2, pp. 136-170.

Stauss, B. and Weinlich, B. (1997). Process-Oriented Measurement of Service Quality: Applying the Sequential Incident Technique, European Journal of Marketing, Vol. 31, No. 1, pp. 3355.

Stewart, T.R. (1987). The Delphi Technique and Judgmental Forecasting. Climatic Change, Vol. 11, No. 1-2, pp. 97-113.

Strauss, H.J. and Zeigler, L.H. (1975). The Delphi Technique and its Uses in Social Science Research. Journal of Creative Behavior, Vol. 9, No. 4, pp. 253-259.

Taylor, M. S. and Enz, C. A. (2002) GMs', Responses to the Events of September 11, 2001, Cornell Hotel and Restaurant Administration Quarterly, Vol. 43, No. 7, pp. 7-20.

Thomas, W.J. (2006). The Vioxx Story: Would It Have Ended Differently in the European Union? American Journal of Law and Medicine, Vol. 32, No. 2-3, pp. 365-380.

Thompson, C.J., Locander, W.B. and Pollio, H.R. (1989). Putting Consumer Experience back into Consumer Research: The Philosophy and Method of Existential Phenomenology, Journal of Consumer Research, Vol.16, No.2, pp. 33-146.

Turoff, M. (1970). The Design of a Policy Delphi, Technological Forecasting and Social Change, Vol. 2, No. 2, pp. 149-172.

Turoff, M. (2002). The Policy Delphi. In H.A. Linstone and M. Turoff (eds.). The Delphi Method: Techniques and Applications, Reading MA: Addison-Wesley, pp. 80-96.

Webler, T., Levine, D., Rakel, H. and Renn, O. (1991). A Novel Approach to Reducing Uncertainty: The Group Delphi, Technological Forecasting and Social Change, Vol. 39, No. 3, pp. 253-263.

Wikstrom, S. (1978). Information about Consumer Problems by the Policy-Delphi Procedure. A New Method for Evaluating the Marketing System. Advances in Consumer Research, Vol. 5, No. 1, pp. 596-602.

Wirtz, J., Kum, D. and Lee, K.S. (2000). Should a Firm with a Reputation for Outstanding Service Quality Offer a Service Guarantee? Journal of Services Marketing, Vol. 14, No. 6, pp. 502-512.

Wood, G.D. and Ellis, R.C.T., (2003). Risk Management Practices of Leading UK Cost Consultants. Engineering, Construction and Architectural Management, Vol. 10, No. 4, pp. 254-262. 
Yong, Y.W., Keng, K.A., Leng, T.L. (1988). A Delphi Forecast for the Singapore Tourism Industry: Future Scenario and Marketing Implications, International Marketing Review, Vol. 6, No. 3, pp. 35-46.

Young, W. B. and Montgomery, R. J. (1998). Crisis Management And Its Impact On Destination Marketing: A Guide to Convention and Visitors Bureaus, Journal of Convention and Exhibition Management, Vol. 1, No. 1, pp. 3-18.

Zeithaml, V.A. and Bitner, M.J. (2003). Services Marketing: Integrating Customer Focus across the Firm, (3rd edition). New York: McGraw-Hill.

Zschau, J. and Küppers, A.N. (2003). Early Warning Systems for Natural Disaster Reduction, Heidelberg: Springer-Verlag. 